\title{
Origin and Biology of the Allogeneic Response
}

\author{
Fadi G. Lakkis ${ }^{1}$ and Robert I. Lechler ${ }^{2}$ \\ ${ }^{1}$ Thomas E. Starzl Transplantation Institute, University of Pittsburgh School of Medicine, Pittsburgh, \\ Pennsylvania 15238 \\ ${ }^{2}$ King's College London, Counting House, Guy's Hospital, Great Maze Pond SE1 9RT, United Kingdom \\ Correspondence: lakkisf@upmc.edu
}

\begin{abstract}
The recognition by the immune system of nonself determinants on cells, tissues, or organs transplanted between genetically disparate members of the same species can lead to a potent allogeneic response that is responsible for rejection. We review here fundamental concepts that underlie the origins and biology of allorecognition in the mammalian immune system. We examine why and how T cells are alloreactive and discuss emerging evidence of allorecognition by innate immune cells. The nature of T cells (naïve vs. memory) and the alloantigen presentation pathways (direct, indirect, and semidirect) that initiate the allogeneic response are outlined.
\end{abstract}

$T_{\mathrm{r}}^{\mathrm{h}}$ he defense systems of all studied metazoans, ranging from sponges to humans, possess the inherent ability to recognize and reject cells or tissues of genetically disparate members of the same species (Burnet 1971; Hildemann 1974; Rosengarten and Nicotra 2011). This phenomenon, referred to as the allogeneic response, constitutes the principal barrier to the spontaneous acceptance of organs transplanted from one human to another. In this article, we address two fundamental problems in transplantation immunology. First is the origin of allorecognition (or why we are alloreactive), and second is the mechanism of allorecognition (or how the immune system recognizes a transplanted organ). Satisfactory resolution of these problems is key to uncovering the primary steps required for initiating allograft rejection and to advancing therapy in clinical transplantation.

\section{ORIGINS OF ALLORECOGNITION: WHY ARE WE ALLOREACTIVE?}

A defining feature of the mammalian allogeneic response is the central role that $\mathrm{T}$ cells play in both the afferent and efferent phases of the response. Studies in neonatally thymectomized and subsequently irradiated adult mice established that $\mathrm{T}$ cells are the sine qua non of allograft rejection (Miller 1962; Hall et al. 1978a,b). The subsequent and well-justified T-cell focus of transplantation researchers led to most of the advances in our understanding of the allogeneic response and to effective antirejection therapies in the clinic, but at the same time overshadowed potentially important allorecognition phenomena that predate $\mathrm{T}$ cells. In this section, we discuss the basis and origins of allorecognition by both $\mathrm{T}$ cells and innate immune cells. We define what is being recognized in the allogeneic

Editors: Laurence A. Turka and Kathryn J. Wood

Additional Perspectives on Transplantation available at www.perspectivesinmedicine.org

Copyright (C) 2013 Cold Spring Harbor Laboratory Press; all rights reserved; doi: 10.1101/cshperspect.a014993

Cite this article as Cold Spring Harb Perspect Med 2013;3:a014993 
F.G. Lakkis and R.I. Lechler

response, why $\mathrm{T}$ cells are alloreactive, and venture into the less charted territory of allorecognition by innate immune cells.

\section{What Is Allogeneic Nonself?}

In the broadest sense, allogeneic nonself is any antigen or group of antigens expressed on donor but not recipient tissues that is responsible for graft rejection. Major histocompatibility complex (MHC) proteins occupy a central position among alloantigens because they are highly polymorphic, ubiquitously expressed, and capable of eliciting unusually large polyclonal T-cell responses (Sherman and Chattopadhyay 1993) (see "Why Are T Cells Alloreactive?"). Careful matching at MHC loci between donors and recipients prolongs allograft survival in immunosuppressed recipients but does not lead to spontaneous graft acceptance (Takemoto et al. 2000). Other polymorphic molecules known as minor histocompatibility antigens (mHAgs) that are unrelated to the MHC also trigger graft rejection (Dierselhuis and Goulmy 2009). mHAgs range from proteins encoded by mitochondrial DNA to those encoded virtually anywhere in the nuclear genome (e.g., the $\mathrm{H}-\mathrm{Y}$ antigen encoded on the $\mathrm{Y}$ chromosome). Although a single nonself-mHAg induces a much more limited $\mathrm{T}$-cell response than that caused by a single nonself-MHC antigen, the presence of numerous mHAg mismatches in otherwise MHC-matched donor-recipient pairs almost invariably leads to rapid graft rejection (Peugh et al. 1986). These fundamental observations underscore the fact that allogeneic nonself is not restricted to foreign MHC molecules but that it encompasses non-MHC molecules expressed in the donor but not shared by the recipient.

\section{Why Are T Cells Alloreactive?}

The mammalian immune system has presumably evolved to recognize and eliminate microbial pathogens (Janeway 2001). It is therefore not surprising that the T-cell repertoires of all studied mammals have the capacity to respond to countless microbes, but why is it that these same repertoires also react vigorously to allogeneic grafts? The answer lies in our understanding of the molecular mechanisms by which $\mathrm{T}$ cells recognize foreign antigens. T cells detect foreign antigens via T-cell receptors (TCRs) for antigens generated by random somatic gene arrangement during T-cell development. TCRs do not engage whole antigens but instead bind to antigen-derived peptides complexed to selfMHC molecules, a phenomenon known as selfrestricted antigen recognition (Yin et al. 2012). The TCR:MHC + peptide interaction is dependent on recognition by the TCRs of amino acid residues present in both the bound peptide and the regions of the MHC molecule surrounding the peptide-binding groove. The immense variety of randomly generated TCRs and the fact that multiple MHC genes and both alleles of each MHC gene are coexpressed in any given individual enable the $\mathrm{T}$-cell repertoire to react to a vast array of self-MHC + nonselfpeptide combinations. This arrangement confers the organism with protection against microbial pathogens but at the same time enables it to respond to nonmicrobial foreign peptides complexed to self-MHC. The latter include allopeptides derived from nonself-mHAg or nonself-MHC molecules that elicit graft rejection. Therefore, alloreactivity is an unavoidable consequence of the random process by which TCRs arise.

Another and perhaps more striking feature of the T-cell repertoire is its ability to react to cells bearing intact foreign $\mathrm{MHC}$ molecules via recognition of nonself-MHC + peptide complexes (Sherman and Chattopadhyay 1993). This property, referred to as "direct" alloreactivity, has been the subject of intense study because it defies the accepted paradigm that during ontogeny only T cells that recognize self-MHC are selected in the thymus to populate the mature repertoire (so-called positive selection). Although multiple hypotheses were originally proposed to account for the presence of these unusual T cells (Sherman and Chattopadhyay 1993), it is now established that they are part of the usual selfrestricted T-cell repertoire. Direct alloreactivity, it turns out, is the result of cross-reactivity (or degeneracy) of TCRs that bind self-MHC + 
nonself-peptide with nonself-MHC + peptide complexes (Yin and Mariuzza 2009). The majority of peptides in the latter are derived from endogenous self-proteins, implying that foreignness can also be dictated by surrounding amino acid residues in the MHC molecule. Polymorphic residues located within the peptide-binding groove of the $\mathrm{MHC}$ molecule also profoundly affect selection of bound peptides, further amplifying differences between histoincompatible individuals. Molecular modeling and more recent $\mathrm{X}$-ray crystallographic analyses have confirmed that the portion of the TCR involved in recognition of nonself-MHC + peptide is the same as that involved in the recognition of self-MHC + nonself-peptide (Macdonald et al. 2009). At the molecular level, therefore, direct T-cell recognition of intact foreign MHC molecules is identical to the recognition of other foreign antigens presented in the context of self-MHC. Moreover, both scenarios arise from the inherent reactivity of $\mathrm{T}$ cells to $\mathrm{MHC}$ molecules (Yin et al. 2012). Raulet and colleagues showed more than 15 years ago that the high propensity of the mature T-cell repertoire to recognize cells expressing MHC molecules is already manifest in immature $\mathrm{T}$ cells that have undergone TCR gene rearrangement but have not yet been subject to thymic selection (the so-called preselection or germline repertoire) (Zerrahn et al. 1997). They found that reactivity to both self- and nonself-MHC molecules occurs at equally high frequencies in the preselection and postselection (mature) repertoires. More recently, the Marrack group provided evidence that TCR variable elements have indeed been selected by evolution to react with MHC proteins (Scott-Browne et al. 2011). The inherent bias of TCRs to "see" self-MHC is advantageous to the organism because it prepares $\mathrm{T}$ cells for positive selection in the thymus but, at the same time, is not conducive to the transplantation of allogeneic tissues because the same TCRs are cross-reactive with nonself-MHC molecules. Direct alloreactivity is therefore an unavoidable consequence of a TCR gene rearrangement process that creates a high frequency of $\mathrm{T}$ cells recognizing both self- and nonselfMHC molecules.
In summary, two forms of allorecognition of foreign MHC molecules exist. The first involves recognition by $\mathrm{T}$ cells of intact nonselfMHC molecules complexed to endogenous peptides. This is known as "direct" allorecognition and is characterized by uniquely high frequencies of responding $\mathrm{T}$ cells for the reasons outlined above. The second pathway involves the recognition of allogeneic MHC molecules as peptides presented by self-MHC molecules. This is referred to as "indirect" allorecognition, because it requires an intermediate antigen processing step; however, it could equally be referred to as "self-restricted" allorecognition because it is indistinguishable from the events that lead to recognition of all other protein antigens. The indirect pathway is in many regards similar to the recognition of mHAg; however, there is one factor that makes the indirect recognition of MHC alloantigens categorically distinct, and that is the role of allospecific B cells. One hallmark of mHAgs is that they are much less likely to provoke antibody responses, reflecting the fact that they are peptides derived from intracellular proteins. However, MHC alloantigens are readily bound by surface immunoglobulin on $B$ cells. Indeed, when this occurs, and the allospecific B cell internalizes and processes the MHC molecule, this leads to indirect presentation by the B cell of allogeneic MHC peptides by the B cell's own MHC class II molecules. Given the efficiency of antigen-specific B cells as antigen-presenting cells (see "Role of Recipient $\mathrm{B}$ Cells"), this represents an important route of amplifying what is otherwise a relatively weak immune response. Both types of allorecognition owe their origins to the fundamental processes that generate a diverse mature T-cell repertoire. The first arises because TCR gene rearrangement is random and extensive, and the second because TCR gene rearrangement preferentially generates TCRs that bind MHC molecules, which enables $T$ cells to undergo positive selection in the thymus. Thus, the elements of the adaptive immune response selected over evolutionary time to provide the organism with maximal protection against infection (TCR gene rearrangement, thymic T-cell selection, extreme polymorphism of the MHC, and self-restricted 
F.G. Lakkis and R.I. Lechler

antigen recognition) are one and the same as those that underlie T-cell alloreactivity.

\section{Are Innate Cells Alloreactive?}

In a now classical monograph published in 1989 (Janeway 1989), Charles Janeway posited that nonself recognition extends beyond somatically rearranged receptors on $\mathrm{T}$ and $\mathrm{B}$ lymphocytes to germline-encoded pattern-recognition receptors on cells of the innate immune system. He postulated that these pattern recognition receptors, commonly referred to by the acronym PRR, detect conserved pathogen-associated molecular patterns (PAMPs) not shared by mammalian cells. Engaging PRRs by PAMPs, he predicted, not only triggers immediate innate defenses against microbes (e.g., phagocytosis and acute inflammation) but also induces the maturation of antigen-presenting cells (APCs). These, in turn, present microbial peptides to $\mathrm{T}$ cells and provide the costimulatory signals necessary for full T-cell activation. Janeway's predictions were rapidly borne out by the discovery of several families of PRR - the Toll-like receptor (TLR) family being a prime examplethat detect specific classes of microbial products (e.g., lipopolysaccharide and viral nucleic acids) and trigger both inflammation and APC maturation (Beutler 2009; Palm and Medzhitov 2009). Therefore, the innate immune system as we know it now is not only a first-line defense system synonymous with inflammation but one that distinguishes between self and nonself and initiates the adaptive immune response. The new paradigm raises the fundamental question whether innate immune recognition extends beyond microbial detection to the detection of allogeneic nonself, and, if so, how is this advantageous to the host?

Two lines of evidence support the existence of innate allorecognition mechanisms. First, allograft rejection is not restricted to vertebrate animals endowed with adaptive immune systems but is common to many invertebrate organisms that predate the evolution of adaptive immunity (animals that lack T and B lymphocytes, NK cells, somatic gene rearrangement enzymes, and the MHC). Sessile, colonial marine invertebrates in at least four different phyla or subphyla (Porifera, sponges; Cnidaria, corals and hydroids; Bryozoa, sea mats; and Urochordata, tunicates or sea squirts) distinguish between their own tissues and those of unrelated members of the same species (Rosengarten and Nicotra 2011). Physical contact between two unrelated, genetically disparate colonies results in a rejection response, in which one colony induces the death of its opponent using specialized effector cells or establishes a barrier between itself and its opponent. If the interacting colonies are closely related (e.g., siblings), they fuse their tissues to become a physiologically integrated, chimeric individual. The genes or gene complexes responsible for allorecognition have been identified in two colonial marine invertebrates: the Cnidarian Hydractinia symbiolongicarpus and the Urochordate Botryllus schlosseri (De Tomaso et al. 2005; Nicotra et al. 2009; Rosa et al. 2010). In both organisms, overt rejection occurs if the interacting colonies do not share any allorecognition alleles and is inhibited if they share at least one haplotype (one set of alleles inherited from one parent) (Mokady and Buss 1996; McKitrick et al. 2011). These observations are reminiscent of NK responses in mice and humans, in which NK cells are inhibited by self-MHC molecules but are free to mount a cytotoxic attack if self$\mathrm{MHC}$ is missing. Allorecognition in Hydractinia is determined by at least two highly polymorphic, allorecognition genes that reside in an immunoglobulin superfamily gene-rich complex and code for transmembrane proteins containing extracellular immunoglobulin-like domains, but neither the Hydractinia nor Botryllus allorecognition molecules have mammalian homologs (De Tomaso et al. 2005; Nicotra et al. 2009; Rosa et al. 2010). Therefore, the discovery of invertebrate allorecognition systems leaves us with the intriguing possibility that similar systems or remnants thereof have been conserved in vertebrates but does not provide direct clues to what they could be.

A second and perhaps more direct line of evidence that the mammalian innate immune system responds to allogeneic nonself derives from transplantation studies in mice devoid of lymphoid cells. Zecher et al. (2009) showed that 
injecting allogeneic splenocytes into the ear pinnae of $\mathrm{RAG}^{-/-}$mice, which lack T and B lymphocytes, elicits significantly greater swelling and infiltration of the skin with host myeloid cells than injecting syngeneic splenocytes. Maximal response to allogeneic cells required prior priming with alloantigen, showed crude specificity (donor-specific recall response $>$ thirdparty response), occurred independent of NK cells and was mediated by monocytes. In this model, the monocyte response was to allodeterminants not linked to the MHC. A follow-up study showed that heart allografts transplanted to $\mathrm{\gamma c}^{-/-} \mathrm{RAG}^{-/-}$mice, which lack $\mathrm{T}, \mathrm{B}$, and NK cells, are rapidly infiltrated by host monocytes that differentiate into mature, IL-12expressing dendritic cells (DCs) (Zeng et al. 2012). The mature DCs presented antigen to $T$ lymphocytes, driving their proliferation and differentiation to IFN- $\gamma$-producing cells. In contrast, syngeneic grafts elicited transient and limited monocytes to DC differentiation, and the DCs neither expressed IL-12 nor induced IFN- $\gamma$ production by T cells. In vivo exposure of monocytes to allogeneic nonself precipitated $\mathrm{T}$ cell-mediated rejection of single mHAg-mismatched grafts that are otherwise accepted by the host. These findings lend support to the hypothesis that, akin to the Janeway paradigm of innate microbial recognition, innate sensing of allogeneic nonself induces the maturation of APCs that then stimulate adaptive immunity. The allodeterminants that trigger APC maturation and the putative monocyte receptors that recognize them are not known yet.

In summary, there is mounting evidence that the mammalian innate immune system responds to allogeneic nonself independent of $\mathrm{T}$, $B$, and NK cells. This form of allorecognition may initiate or amplify the responses of recipient $\mathrm{T}$ cells to MHC and mHAg alloantigens by inducing the maturation of APCs. It could also provide phagocytic cells with the means to kill allogeneic targets without inflicting damage on self-tissues (Liu et al. 2012). The ubiquity of allorecognition phenomena among sessile, colonial marine animals tempts one to speculate that mammalian innate allorecognition originated in invertebrate ancestors that routinely engaged in conspecific interactions in their natural habitats (Dishaw and Litman 2009). Allorecognition in these primitive ancestors not only conferred the ability to exclude unrelated individuals from one's living space-thus, enhancing survival, growth, and reproductive potential of the defending individual—but also provided safeguards against somatic and stem cell parasitism by preventing the fusion of genetically disparate individuals (Buss 1982; Laird et al. 2005; Poudyal et al. 2007). Fifty years ago, Sir Macfarlane Burnet (Burnet 1971) suggested that "a viviparously produced embryo in the wrong place might become a damaging parasite." Is it possible, then, that innate allorecognition systems were conserved in viviparous vertebrates to survey the maternal decidua for incipient invasion by fetal cells? Further studies are necessary to test this hypothesis.

\section{MECHANISMS OF ALLORECOGNITION: HOW DOES THE IMMUNE SYSTEM RECOGNIZE A TRANSPLANTED ORGAN?}

The accepted view is that the allogeneic response is initiated when host alloreactive T cells recognize alloantigens presented by mature APCs that originate from either the graft (donor APCs) or the recipient (recipient APCs) (Safinia et al. 2010). These distinct alloantigen presentation pathways have been dubbed "direct" and "indirect," respectively, because donor APCs, which express nonself-MHC molecules, interact with "directly" alloreactive T cells, whereas recipient APCs, which process and present allopeptides in the context self-MHC molecules, engage "indirectly" alloreactive T cells (Fig. 1) (Auchincloss and Sultan 1996). More recently, a third pathway of alloantigen presentation has been uncovered in which recipient APCs acquire intact allogeneic MHC-peptide complexes from donor cells and present them to directly reactive recipient T cells (Fig. 1) (Herrera et al. 2004). The latter pathway is referred to as the "semidirect" or "cross-dressing" pathway to differentiate it from the "true" direct pathway performed by donor APCs and has also been shown to participate in initiating antiviral immunity (Wakim and Bevan 2011). Much research in 
F.G. Lakkis and R.I. Lechler

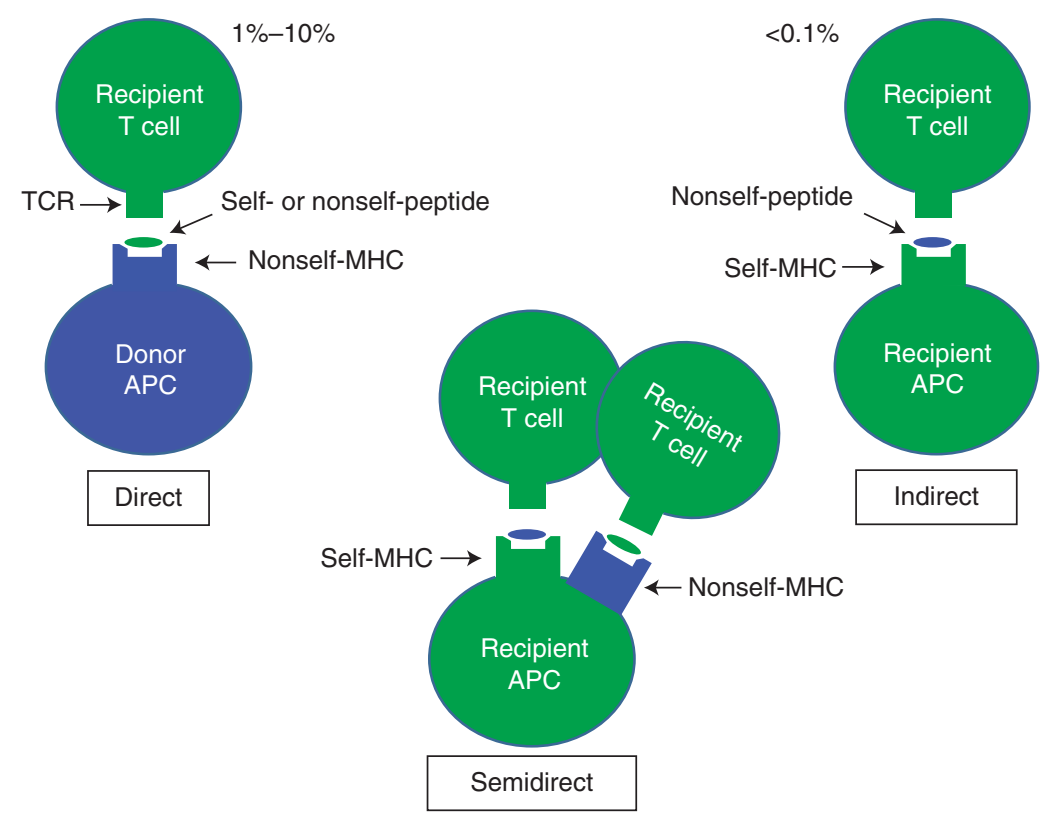

Figure 1. Pathways of alloantigen presentation. The three pathways of alloantigen presentation (direct, indirect, and semidirect) are shown. The frequency (\%) of $\mathrm{T}$ cells that react to a specific pathway is indicated where known. APC, antigen-presenting cell; MHC, major histocompatibility complex molecule; TCR, T-cell receptor for antigen. (From Kaplan et al. 2012; reprinted, with permission, from John Wiley and Sons (C) 2012.)

transplantation has been dedicated to understanding these pathways and their relative contributions to acute and chronic rejection of solid organ allografts. Here we summarize salient observations and controversies in this area by asking which $\mathrm{T}$ cell and which APC are indeed instrumental to the recognition of transplanted organs.

\section{Which T Cell?}

$\mathrm{T}$ cells come in two general flavors: naïve and memory (Sallusto et al. 2010). Naïve T cells mount primary immune responses to foreign antigens not previously encountered by the host. They are present at a low precursor frequency for any given antigen, have a relatively high stimulation threshold, and can only be activated within secondary lymphoid tissues (Lakkis et al. 2000). Memory T cells, in contrast, mount secondary immune responses to antigens previously encountered by the individual, for example, after vaccination or infection.
Memory $\mathrm{T}$ cells are long-lived lymphocytes that exist at a greater frequency for previously encountered antigens than their naïve counterparts, have a low stimulation threshold, a high proliferative capacity, and can be activated within secondary lymphoid tissues or at nonlymphoid sites-for example, within the allograft itself (Chalasani et al. 2002). Memory T-cell responses are therefore faster and more vigorous than naïve $\mathrm{T}$-cell responses.

A key, albeit surprising, observation is that the allogeneic T-cell response in humans is not truly naïve but also includes memory $\mathrm{T}$ cells. Merkenschlager et al. (1988) and Lombardi et al. (1990) independently showed more than 20 years ago that the memory T-cell pool in individuals not previously exposed to alloantigens contains a high frequency of alloreactive $\mathrm{T}$ cells, equivalent to that observed in the naïve pool. The same observation was confirmed many years later in a larger group of healthy volunteers, and, as suspected, alloreactive memory $\mathrm{T}$ cells were shown to be cross-reactive memory 
$\mathrm{T}$ cells that possess antimicrobial specificities (Macedo et al. 2009)—a phenomenon known as heterologous immunity (Ford and Larsen 2010). The participation of memory $\mathrm{T}$ cells in the allogeneic response, along with the polyclonality of alloreactive T cells (see "Origins of Allorecognition: Why Are We Alloreactive?"), contributes to the touted vigor of the "primary" allogeneic response both in vitro and in vivo. The memory feature of the allogeneic response also has important implications for how transplanted organs are recognized. Although the activation of naïve $\mathrm{T}$ cells is clearly dependent on encountering antigen presented by professional APCs (e.g., DCs) within secondary lymphoid tissues (Lakkis et al. 2000), memory T cells can be activated within the transplanted organ itself, and, importantly, their activation may or may not require professional APCs or the costimulatory stimuli that they provide (Chalasani et al. 2002). These issues are revisited in the next section in the context of which APC initiates allogeneic responses.

\section{Which APC?}

Antigen presentation, defined broadly as the ability to present either endogenous or exogenous antigens and activate $\mathrm{T}$ cells, can be shown in multiple cell types. First are the so-called professional APCs that include DCs (reportedly the most potent antigen-presenting cells) and phagocytic cells distributed throughout the body (e.g., macrophages). Second are endothelial cells, which when activated by inflammatory or immune stimuli, particularly in humans, acquire antigen-presenting function (Pober and Tellides 2012). Third are B lymphocytes, which although much less potent than DCs, proliferate in response to antigens and provide abundant total antigen-presenting capacity. So what roles do these different types of APCs have in the allogeneic response?

\section{Role of Donor versus Recipient DCs}

Historically, donor DCs that accompany the graft have been regarded as the dominant APC type responsible for initiating primary allogene- ic responses. Evidence that grafts contain migratory, bone-marrow-derived, or "passenger" leukocytes that prime the recipient against graft antigens originated in the 1950s and was subsequently buttressed by seminal experiments in rodents (Snell 1957). Lafferty and coworkers showed that depletion of passenger leukocytes by in vitro culture prolongs the survival of thyroid and pancreatic islet grafts transplanted to allogeneic hosts (Lafferty et al. 1976; Talmage et al. 1976; Bowen et al. 1980). In 1982, Lechler and Batchelor (1982a,b) identified that DCs were the passenger leukocytes most likely responsible for priming the naïve host. They showed that renal allografts are accepted longterm by immunocompetent rats if first parked in an intermediate immunosuppressed host to deplete passenger leukocytes (Lechler and Batchelor 1982a). The transfer of donor-type DCs to the immunocompetent host resulted in T-cell priming and rejection of the grafts (Lechler and Batchelor 1982b), providing for the first time a cause-effect relationship between donor DCs and initiation of the allogeneic response. Proof that DCs, indeed, migrate out of grafts to the recipient's secondary lymphoid tissues shortly after transplantation provided further support for this hypothesis (Larsen et al. 1990a,b).

The primacy of donor DCs in initiating rejection was, however, called into question when it was observed that, in certain donor-recipient strain combinations, donor DC-depleted rat kidney grafts could provoke a rejection response, albeit more slowly, than DC-replete grafts. This led to the first postulation of the indirect pathway of allorecognition. This was subsequently shown using MHC gene knockout mice as graft donors to block antigen presentation by donor DCs or by introducing MHC-derived peptides rather than intact MHC molecules into the recipient; several groups showed that acute rejection, albeit sometimes of a slower nature, can be initiated by the indirect pathway alone (Auchincloss et al. 1993; Benham et al. 1995; Valujskikh et al. 1998). The indirect pathway of alloantigen presentation was subsequently shown to play a role in the pathogenesis of chronic allograft rejection (Safinia et al. 2010), a concept that is 
commensurate with the observation that direct presentation dwindles rapidly after transplantation because donor DCs that migrate to secondary lymphoid tissues are eliminated by recipient NK cells (Garrod et al. 2007). The view therefore emerged that direct alloantigen presentation is sufficient but not necessary for initiating acute rejection, whereas indirect alloantigen presentation contributes to acute rejection and may be the key driver of chronic rejection.

The recent development of transgenic mice in which DCs can be selectively deleted has provided the opportunity to test the roles of donor and recipient DCs in the allogeneic response directly. One early study has yielded surprising results. Using CD11c-DTR mice, in which the administration of diphtheria toxin (DT) deletes DCs because they express the transgene for the human diphtheria toxin receptor (DTR), Garrod et al. (2010) showed that donor DC depletion does not have an effect on acute cardiac allograft rejection, but recipient DC depletion prevents acute rejection and prolongs graft survival significantly. In the same study, the investigators showed that donor DCs are surrounded and killed by recipient NK cells very early after their migration to secondary lymphoid tissues, rendering direct alloantigen presentation a limited process at best. These findings suggest that recipient rather than donor DCs are necessary and sufficient for initiating acute rejection. It is possible that donor DCs deliver their antigenic cargo to recipient DCs in secondary lymphoid tissue either in the form of shed proteins that are then taken up and presented via the indirect pathway, or via exosomes that fuse to recipient DCs allowing for nonself-MHC presentation via the semidirect pathway (Smyth et al. 2007; Montecalvo et al. 2008). This model implies that a single recipient DC can stimulate indirectly reactive CD4 and directly reactive CD8 $\mathrm{T}$ cells at the same time, providing optimal CD4 help to CD8 T cells. The transfer of alloantigens from donor to recipient DCs may also be important for the induction of transplantation tolerance, for example, in experimental animals injected with tolerogenic donor DCs (Divito et al. 2010). Whether recipient DCs are indeed necessary for inducing alloimmunity or tolerance, however, should be validated in models other than the CD11c-DTR mouse because the CD11c promoter could potentially drive DTR expression on a variety of nondendritic cells (Satpathy et al. 2012).

\section{Role of Graft Endothelium}

Studies on the role of DCs in initiating allogeneic responses have been largely restricted to naïve laboratory rats and mice whose T-cell repertoires contain only a small percentage of memory cells. Humans, in contrast, possess much larger populations of memory $\mathrm{T}$ cells generated by repeated exposure to microbial infection. Because cross-reactive memory $\mathrm{T}$ cells contribute considerably to the primary alloimmune response in humans and have less stringent activation requirements than their naïve counterparts (see section, "Which T Cell?"), one is left wondering whether initiation of the human allogeneic response follows the same rules as in rodents? Pober, Tellides, and coworkers have long championed the hypothesis that the graft endothelium plays a central role in presenting antigen to and activating human alloreactive memory T cells (Pober and Tellides 2012). Their investigations, as well as those of others, have provided evidence that human endothelial cells express both MHC and costimulatory molecules, present antigens, and induce the activation and differentiation of memory CD4 and CD8 T cells ( Shiao et al. 2007; Dengler and Pober 2008). Because the graft endothelium is presumably where circulating memory $\mathrm{T}$ cells first contact graft antigens, it is postulated that allogeneic responses could be initiated by endothelial cells, independent of DCs or other bone-marrow-derived APCs. Corroborating evidence that the graft endothelium is sufficient for activating directly alloreactive CD8 T cells exists in the mouse (Kreisel et al. 2002). An additional contribution of endothelial cell alloantigen presentation to transplant immunity has been referred to as the "shop window" effect. The vascular endothelium displays, as MHC-presented peptides, some of the contents within the tissue through which the vessel runs, and may accelerate, or in fact initiate, the transmigration of T cells specific 
for endothelial cell-displayed antigens. This has been shown to be true both in vitro and, using intravital microscopy, in vivo (Marelli-Berg et al. 2004; Walch et al. 2013). Gradual replacement of a small but significant proportion of donor endothelial cells with recipient cells over time suggests that the graft endothelium could also participate in indirect alloantigen presentation (Valujskikh et al. 2002). Additional studies, however, are needed to dissect which APC (DC or endothelial cell) is necessary and/or sufficient for the activation of alloreactive memory $\mathrm{T}$ cells after transplantation. Such studies are expected to have important clinical implications because of the conspicuous role that alloreactive memory $\mathrm{T}$ cells have in human allograft rejection in both naïve and sensitized recipients.

\section{Role of Recipient B Cells}

B-cell depletion in mice or humans does not prevent or delay acute T-cell-mediated rejection and, in some cases, could actually increase the risk of rejection (Tydén et al. 2009). There is mounting evidence, however, that B cells are required for maximal generation of memory $\mathrm{T}$ cells after either organ transplantation or microbial infection and that this effect is due to their antigen-presenting function (Lund and Randall 2010; Ng et al. 2010). Moreover, recipient B cells have been recently found to be instrumental for the pathogenesis of chronic heart allograft rejection in mice independent of alloantibody production (Sheriff et al. 2011). Therefore, B cells are not essential for initiating allogeneic responses but could have an important role in chronic rejection, possibly by providing longterm indirect alloantigen presentation to T cells.

\section{CONCLUDING REMARKS}

Allogeneic responses are potent immune responses that cause allograft rejection. They are characteristically polyclonal, involving many TCR specificities, and are brought about by the activation of both naïve and preexisting, crossreactive memory $\mathrm{T}$ cells. Importantly, the alloreactive T-cell repertoire, whether "directly" or "indirectly" alloreactive, is one and the same as the "normal" T-cell repertoire devoted to the recognition of antigens in the context of self-MHC molecules. Both "directly" and "indirectly" alloreactive $\mathrm{T}$ cells bind to their target MHC-peptide complexes with the same molecular mechanisms. Mounting evidence suggests that allorecognition is not restricted to the adaptive immune system but that it may be an inherent property of the innate immune system as well. Cells or tissues transplanted from allogeneic donors induce the differentiation of host monocytes to mature DCs independent of T, B, and NK cells. These DCs play a key role in initiating T-cell-dependent rejection. Finally, despite long-standing emphasis on direct and indirect alloantigen presentation as independent processes competing for the attention of transplant immunologists, more recent evidence points to extensive antigen transfer between donor and recipient cells. The transfer of intact MHC molecules from graft cells, possibly donor DCs, to recipient DCs, for example, may have an important role in activating the allogeneic response. These and other unresolved questions highlighted in this review warrant further study, even if it entails exploring unorthodox ideas that lie outside the safe confines of our field.

\section{REFERENCES}

Auchincloss H Jr, Sultan H. 1996. Antigen processing and presentation in transplantation. Curr Opin Immunol 8: 681-687.

Auchincloss H, Lee R, Shea S, Markowitz JS, Grusby MJ, Glimcher LH. 1993. The role of "indirect" recognition in initiating rejection of skin grafts from major histocompatibility complex class II-deficient mice. Proc Natl Acad Sci 90: 3373-3377.

Benham AM, Sawyer GJ, Fabre JW. 1995. Indirect T cell allorecognition of donor antigens contributes to the rejection of vascularized kidney allografts. Transplantation 59: $1028-1032$.

Beutler BA. 2009. TLRs and innate immunity. Blood 113: 1399-1407.

Bowen KM, Andrus L, Lafferty KJ. 1980. Successful allotransplantation of mouse pancreatic islets to nonimmunosuppressed recipients. Diabetes 29 (Suppl): 98-104.

Burnet FM. 1971. "Self-recognition" in colonial marine forms and flowering plants in relation to the evolution of immunity. Nature 232: 230-235.

Buss L. 1982. Somatic cell parasitism and the evolution of somatic tissue compatibility. Proc Natl Acad Sci 79: 5337-5341. 
F.G. Lakkis and R.I. Lechler

Chalasani G, Dai Z, Konieczny BT, Baddoura FK, Lakkis FG. 2002. Recall and propagation of allospecific memory $\mathrm{T}$ cells independent of secondary lymphoid organs. Proc Natl Acad Sci 99: 6175-6180.

Dengler TJ, Pober JS. 2008. Human vascular endothelial cells stimulate memory but not naive $\mathrm{CD} 8^{+} \mathrm{T}$ cells to differentiate into CTL retaining an early activation phenotype. J Immunol 164: 5146-5155.

De Tomaso AW, Nyholm SV, Palmeri KJ, Ishizuka KJ, Ludington WB, Mitchel K, Weissman IL. 2005. Isolation and characterization of a protochordate histocompatibility locus. Nature 438: 454-459.

Dierselhuis M, Goulmy E. 2009. The relevance of minor histocompatibility antigens in solid organ transplantation. Curr Opin Organ Transplant 14: 419-425.

Dishaw LJ, Litman GW. 2009. Invertebrate allorecognition: The origins of histocompatibility. Curr Biol 19: R286R288.

Divito SJ, Wang Z, Shufesky WJ, Liu Q, Tkacheva OA, Montecalvo A, Erdos G, Larregina AT, Morelli AE. 2010. Endogenous dendritic cells mediate the effects of intravenously injected therapeutic immunosuppressive dendritic cells in transplantation. Blood 116: 2694-2705.

Ford ML, Larsen CP. 2010. Overcoming the memory barrier in tolerance induction: Molecular mimicry and functional heterogeneity among pathogen-specific T-cell populations. Curr Opin Organ Transplant 15: 405-410.

Garrod KR, Wei SH, Parker I, Cahalan MD. 2007. Natural killer cells actively patrol peripheral lymph nodes forming stable conjugates to eliminate MHC-mismatched targets. Proc Natl Acad Sci 104: 12081-12086.

Garrod KR, Liu F-C, Forrest LE, Parker I, Kang S-M, Cahalan MD. 2010. NK cell patrolling and elimination of donor-derived dendritic cells favor indirect alloreactivity. Immunol 184: 2329-2336.

Hall BM, Dorsch S, Roser B. 1978a. The cellular basis of allograft rejection in vivo. I. The cellular requirements for first-set rejection of heart grafts. J Exp Med 148: $878-889$.

Hall BM, Dorsch S, Roser B. 1978b. The cellular basis of allograft rejection in vivo. II. The nature of memory cells mediating second set heart graft rejection. J Exp Med 148: 890-902.

Herrera OB, Golshayan D, Tibbott R, Salcido Ochoa F James MJ, Marelli-Berg FM, Lechler RI. 2004. A novel pathway of alloantigen presentation by dendritic cells. J Immunol 173: 4828-4837.

Hildemann WH. 1974. Some new concepts in immunological phylogeny. Nature 250: 116-129.

Janeway CA Jr. 1989. Approaching the asymptote? Evolution and revolution in immunology. Cold Spring Harb Symp Quant Biol 54 (Pt 1): 1-13.

Janeway CJ. 2001. How the immune system works to protect the host from infection. Proc Natl Acad Sci 98: 74617468.

Kaplan B, Burkhart GJ, Lakkis FG, eds. 2012. Immunotherapy in transplantation: Principles and practice, p. 13. Wiley, New York.

Kreisel D, Krupnick AS, Gelman AE, Engels FH, Popma SH, Krasinskas AM, Balsara KR, Szeto WY, Turka LA, Rosengard BR. 2002. Non-hematopoietic allograft cells di- rectly activate $\mathrm{CD} 8^{+} \mathrm{T}$ cells and trigger acute rejection: An alternative mechanism of allorecognition. Nat Med 8: 233-239.

Lafferty KJ, Bootes A, Dart G, Talmage DW. 1976. Effect of organ culture on the survival of thyroid allografts in mice. Transplantation 22: 138-149.

Laird D, De Tomaso A, Weissman I. 2005. Stem cells are unit of natural selection in a colonial ascidian. Cell 123: $1351-$ 1360.

Lakkis FG, Arakelov A, Konieczny BT, Inoue Y. 2000. Immunologic "ignorance" of vascularized organ transplants in the absence of secondary lymphoid tissue. Nat Med 6: 686-688.

Larsen CP, Morris PJ, Austyn JM. 1990a. Migration of dendritic leukocytes from cardiac allografts into host spleens: A novel pathway for initiation of rejection. J Exp Med 171: 307-314.

Larsen CP, Steinman RM, Witmer-Pack M, Hankins DF Morris PJ, Austyn JM. 1990b. Migration and maturation of Langerhans cells in skin transplants and explants. J Exp Med 172: 1483-1493.

Lechler RI, Batchelor JR. 1982a. Immunogenicity of retransplanted rat kidney allografts. Effect of inducing chimerism in the first recipient and quantitative studies on immunosuppression of the second recipient. J Exp Med 156: $1835-1841$

Lechler RI, Batchelor JR. 1982b. Restoration of immunogenicity to passenger cell-depleted kidney allografts by the addition of donor strain dendritic cells. J Exp Med 155: $31-41$.

Liu W, Xiao X, Demirci G, Madsen J, Li XC. 2012. Innate NK cells and macrophages recognize and reject allogeneic nonself in vivo via different mechanisms. J Immunol 188: $2703-2711$.

Lombardi G, Sidhu S, Daly M, Batchelor JR, Makgoba W, Lechler RI. 1990. Are primary alloresponses truly primary? Int Immunol 2: 9-13.

Lund FE, Randall TD. 2010. Effector and regulatory B cells: Modulators of $\mathrm{CD} 4^{+} \mathrm{T}$ cell immunity. Nat Rev Immunol 10: $236-247$.

Macdonald WA, Chen Z, Gras S, Archbold JK, Tynan FE, Clements CS, Bharadwaj M, Kjer-Nielsen L, Saunders PM, Wilce MC, et al. 2009. T cell allorecognition via molecular mimicry. Immunity 31: 897-908.

Macedo C, Orkis EA, Popescu I, Elinoff BD, Zeevi A, Shapiro R, Lakkis FG, Metes D. 2009. Contribution of naïve and memory T-cell populations to the human alloimmune response. Am J Transplant 9: 2057-2066.

Marelli-Berg FM, James MJ, Dangerfield J, Dyson J, Millrain M, Scott D, Simpson E, Nourshargh S, Lechler RI. 2004. Cognate recognition of the endothelium induces HYspecific $\mathrm{CD} 8^{+} \mathrm{T}-$ lymphocyte transendothelial migration (diapedesis) in vivo. Blood 103: 3111-3116.

McKitrick TR, Muscat CC, Pierce JD, Bhattacharya D, De Tomaso AW. 2011. Allorecognition in a basal chordate consists of independent activating and inhibitory pathways. Immunity 34: 616-626.

Merkenschlager M, Terry L, Edwards R, Beverley PC. 1988. Limiting dilution analysis of proliferative responses in human lymphocyte populations defined by the monoclonal antibody UCHL1: Implications for differential 
CD45 expression in T cell memory formation. Eur J Immunol 18: 1653-1661.

Miller JFAP. 1962. Effect of neonatal thymectomy on the immunological responsiveness of the mouse. Proc $R$ Soc Lond B 156: 415-428.

Mokady O, Buss LW. 1996. Transmission genetics of allorecognition in Hydractinia symbiolongicarpus (Cnidaria: Hydrozoa). Genetics 143: 823-827.

Montecalvo A, Shufesky WJ, Stolz DB, Sullivan MG, Wang Z, Divito SJ, Papworth GD, Watkins SC, Robbins PD, Larregina AT, et al. 2008. Exosomes as a short-range mechanism to spread alloantigen between dendritic cells during $\mathrm{T}$ cell allorecognition. J Immunol 180: $3081-$ 3090.

Ng YH, Oberbarnscheidt MH, Chandramoorthy HC, Hoffman R, Chalasani G. 2010. B cells help alloreactive T cells differentiate into memory T cells. Am J Transplant 10: 1970-1980.

Nicotra M, Powell A, Rosengarten R, Moreno M, Grimwood J, Lakkis F, Dellaporta S, Buss L. 2009. A hypervariable invertebrate allodeterminant. Curr Biol 19: 583-589.

Palm NW, Medzhitov R. 2009. Pattern recognition receptors and control of adaptive immunity. Immunol Rev 227: 221-233.

Peugh WN, Superina RA, Wood KJ, Morris PJ. 1986. The role of $\mathrm{H}-2$ and non-H-2 antigens and genes in the rejection of murine cardiac allografts. Immunogenetics 23: 30-37.

Pober JS, Tellides G. 2012. Participation of blood vessel cells in human adaptive immune responses. Trends Immunol 33: 49-57.

Poudyal M, Rosa S, Powell AE, Moreno M, Dellaporta SL, Buss LW, Lakkis FG. 2007. Embryonic chimerism does not induce tolerance in an invertebrate model organism. Proc Natl Acad Sci 104: 4559-4564.

Rosa SF, Powell AE, Rosengarten RD, Nicotra ML, Moreno MA, Grimwood J, Lakkis FG, Dellaporta SL, Buss LW. 2010. Hydractinia allodeterminant alr1 resides in an immunoglobulin superfamily-like gene complex. Curr Biol 20: $1122-1127$.

Rosengarten RD, Nicotra ML. 2011. Model systems of invertebrate allorecognition. Curr Biol 21: R82-R92.

Safinia N, Afzali B, Atalar K, Lombardi G, Lechler RI. 2010. T-cell alloimmunity and chronic allograft dysfunction. Kidney Int Suppl 2010: S2-S12.

Sallusto F, Lanzavecchia A, Araki K, Ahmed R. 2010. From vaccines to memory and back. Immunity 33: 451-463.

Satpathy AT, Wu X, Albring JC, Murphy KM. 2012. Re(de)fining the dendritic cell lineage. Nat Immunol 13: 11451154.

Scott-Browne JP, Crawford F, Young MH, Kappler JW, Marrack P, Gapin L. 2011. Evolutionarily conserved features contribute to $\alpha \beta$ T cell receptor specificity. Immunity 35: 526-535.

Sheriff KA, Zeng Q, Li Q, Ng YH, Marlowe A, Randhawa P, Hoffman R, Chalasani G. 2011. B cells and not antibodies are required for $\mathrm{T}$ cell activation and development of chronic rejection. Am J Transplant 11: 40-41.

Sherman LA, Chattopadhyay S. 1993. The molecular basis of allorecognition. Annu Rev Immunol 11: 385-402.

Shiao SL, Kirkiles-Smith NC, Shepherd BR, McNiff JM, Carr EJ, Pober JS. 2007. Human effector memory $\mathrm{CD}^{+} \mathrm{T}$ cells directly recognize allogeneic endothelial cells in vitro and in vivo. J Immunol 179: 4397-4404.

Smyth LA, Afzali B, Tsang J, Lombardi G, Lechler RI. 2007. Intercellular transfer of MHC and immunological molecules: Molecular mechanisms and biological significance. Am J Transplant 7: 1442-1449.

Snell GD. 1957. The homograft reaction. Annu Rev Microbiol 11: $439-458$.

Takemoto SK, Terasaki PI, Gjertson DW, Cecka JM. 2000. Twelve years' experience with national sharing of HLAmatched cadaveric kidneys for transplantation. $N$ Engl J Med 343: 1078-1084.

Talmage DW, Dart G, Radovich J, Lafferty KJ. 1976. Activation of transplant immunity: Effect of donor leukocytes on thyroid allograft rejection. Science 191: 385-388.

Tydén G, Genberg H, Tollemar J, Ekberg H, Persson NH, Tufveson G, Wadström J, Gäbel M, Mjörnstedt L. 2009. A randomized, doubleblind, placebo-controlled, study of single-dose rituximab as induction in renal transplantation. Transplantation 87: 1325-1329.

Valujskikh A, Matesic D, Gilliam A, Anthony D, Haqqi TM, Heeger PS. 1998. T cells reactive to a single immunodominant self-restricted allopeptide induce skin graft rejection in mice. J Clin Invest 101: 1398-1407.

Valujskikh A, Lantz O, Celli S, Matzinger P, Heeger PS. 2002. Cross-primed $\mathrm{CD} 8^{+} \mathrm{T}$ cells mediate graft rejection via a distinct effector pathway. Nat Immunol 3: 844-851.

Wakim LM, Bevan MJ. 2011. Cross-dressed dendritic cells drive memory $\mathrm{CD}^{+}{ }^{+}$T-cell activation after viral infection. Nature 471: 629-632.

Walch JM, Zeng Q, Li Q, Oberbarnscheidt MH, Hoffman RA, Wiliams AL, Rothstein DM, Shlomchik WD, Kim JV, Camirand G, et al. 2013. Cognate antigen directs CD8 ${ }^{+}$ $\mathrm{T}$ cell migration to vascularized transplants. J Clin Invest 123: 2663-2671.

Yin Y, Mariuzza RA. 2009. The multiple mechanisms of T cell receptor cross-reactivity. Immunity 31: 849-851.

Yin L, Scott-Browne J, Kappler JW, Gapin L, Marrack P. 2012. T cells and their eons-old obsession with MHC. Immunol Rev 250: 49-60.

Zecher D, van Rooijen N, Rothstein D, Shlomchik W, Lakkis F. 2009. An innate response to allogeneic nonself mediated by monocytes. J Immunol 183: 7810-7816.

Zeng Q, Williams AL, Hoffman R, Rothstein DM, Oberbarnscheidt MH, Lakkis F. 2012. Innate recognition of allogeneic non-self induces monocyte differentiation to mature dendritic cells in vivo. Am J Transplant 12: 148 148.

Zerrahn J, Held W, Raulet DH. 1997. The MHC reactivity of the $\mathrm{T}$ cell repertoire prior to positive and negative selection. Cell 88: 627-636. 


\section{$\&_{\mathrm{CSH}}^{\infty} \&$ Cold Spring Harbor

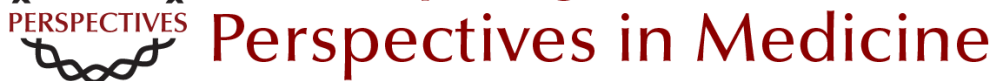

\section{Origin and Biology of the Allogeneic Response}

Fadi G. Lakkis and Robert I. Lechler

Cold Spring Harb Perspect Med 2013; doi: 10.1101/cshperspect.a014993

Subject Collection Transplantation

Heart Transplantation: Challenges Facing the

Field

Makoto Tonsho, Sebastian Michel, Zain Ahmed, et al.

Bioethics of Organ Transplantation Arthur Caplan

Overview of Clinical Lung Transplantation Jonathan C. Yeung and Shaf Keshavjee

Immunological Challenges and Therapies in

Xenotransplantation Marta Vadori and Emanuele Cozzi

Clinical Aspects: Focusing on Key Unique

Organ-Specific Issues of Renal Transplantation Sindhu Chandran and Flavio Vincenti

T-Cell Costimulatory Blockade in Organ

Transplantation Jonathan S. Maltzman and Laurence A. Turka

Regulatory T-Cell Therapy in Transplantation:

Moving to the Clinic

Qizhi Tang and Jeffrey A. Bluestone

Opportunistic Infections--Coming to the Limits of Immunosuppression?

Jay A. Fishman
Overview of the Indications and Contraindications

for Liver Transplantation

Stefan Farkas, Christina Hackl and Hans Jürgen Schlitt

Facial and Hand Allotransplantation Bohdan Pomahac, Ryan M. Gobble and Stefan Schneeberger

Induction of Tolerance through Mixed Chimerism David H. Sachs, Tatsuo Kawai and Megan Sykes

Pancreas Transplantation: Solid Organ and Islet Shruti Mittal, Paul Johnson and Peter Friend

Tolerance--Is It Worth It? Erik B. Finger, Terry B. Strom and Arthur J. Matas

Lessons and Limits of Mouse Models Anita S. Chong, Maria-Luisa Alegre, Michelle L. Miller, et al.

Effector Mechanisms of Rejection Aurélie Moreau, Emilie Varey, Ignacio Anegon, et al.

The Innate Immune System and Transplantation Conrad A. Farrar, Jerzy W. Kupiec-Weglinski and Steven H. Sacks

For additional articles in this collection, see http://perspectivesinmedicine.cshlp.org/cgi/collection/ 